\title{
DELEUZE/GUATTARI/ARTAUD: DEVIR-REVOLUCIONÁRIO E BIOPOTÊNCIA - POR UM OUTRAMENTO DAS FORÇAS INTENSIVAS DE UMA CONTRAFILOFIA
}

\author{
DELEUZE/GUATTARI /ARTAUD: DEVIR-RÉVOLUTIONNAIRE ET BIOPUISSANCE - \\ POUR UNE AUTRE DES FORCES INTENSIVES DE LA CONTREPHILOPHIE
}

\author{
Alex Fabiano Jardim ${ }^{1}$ \\ Michelle Martins de Almeida ${ }^{2}$
}

Resumo: A proposta do trabalho é produzir uma conversação entre Deleuze/Guattari e Artaud. A ideia é pensar Artaud enquanto intercessor, personagem conceitual importante para pensarmos em Deleuze o esgotamento. A valsa da escrita artaudiana, de um corpo sem deus, sem órgãos, sem juízo, nos faz andar à beira de um abismo engenhoso, onde forças que promovem um estrangulamento biopolítico pretendem nos manter no limbo do cansaço. É a experiência do esgotamento de uma vida que não suporta mais os dispositivos que segmentam a sensação do cansaço que pari o devir-revolucionário. Artaud nos faz experimentar o extremo do abandono, do desamparo, do desespero. Ao experimentar o esgotamento, linhas de articulação e de fuga se implicam por devir. Agenciamentos inventados a partir de um outramento de enunciações das mais diversas, levando-nos à dissolução de um Eu. As potências da vida, potências intensivas, seriam liberadas a partir de uma experimentação da inexistência. Palavras-chave: Devir-revolucionário; biopotência; vida.

Resumé: Le but de l'œuvre est de produire une conversation entre Deleuze / Guattari et Artaud. L'idée est de penser Artaud comme un intercesseur, un personnage conceptuel important pour nous permettre de penser l'épuisement de Deleuze. La valse de l'écriture artaudienne, d'un corps sans dieu, sans organes, sans jugement, nous fait marcher au bord d'un gouffre ingénieux, où des forces qui favorisent un étranglement biopolitique entendent nous maintenir dans les limbes de la fatigue. C'est l'expérience de l'épuisement d'une vie qui ne supporte plus les dispositifs qui segmentent la sensation de fatigue qui a donné naissance au révolutionnaire. Artaud nous fait vivre l'extrême de l'abandon, de l'impuissance, du désespoir. En cas d'épuisement, les lignes d'articulation et d'évasion sont impliquées par le devenir. Des agences inventées à partir d'un ensemble différent d'énoncés, conduisant à la dissolution d'un I. Les pouvoirs de la vie, les pouvoirs intensifs, seraient libérés d'une expérience de non-existence.

Clés-mots: Devenir-révolutionnaire; biopuissance; vie.

Eu não sentia a vida, a circulação de toda ideia moral era para mim como um rio seco. A vida não era para mim um objeto, uma forma; ela se tornara para mim uma série de raciocínios. Mas de raciocínios que giravam no vazio, de raciocínios que não giravam, que eram em mim como "esquemas" possíveis que minha vontade não conseguia fixar.

Mesmo para chegar ao estado de suicídio, devo esperar o retorno de meu eu, preciso do livre jogo de

\footnotetext{
${ }^{1}$ Universidade Estadual de Montes Claros, Unimontes, MG.

${ }^{2}$ Universidade Estadual de Montes Claros, Unimontes, MG.
} 
todas as articulações de meu ser. Deus me colocou no desespero como uma constelação de impasses

cuja radiação chega a mim. Eu não posso nem morrer, nem viver, nem desejar morrer ou viver. $E$ todos os homens são como eu. Linguagem e Vida. Antonin Artaud

O corpo artaudiano grita! Uma explosão pelo enclausuramento do corpo, pelo corpo que já não aguenta mais e é preciso ser refeito. Pela dor, angústia e esgotamento. "E todos os ritos para esclerosar, atar, petrificar, amarrar" (ARTAUD, 2017, p. 133) o corpo humano "dentro do módulo de suas estratificações atuais" (ARTAUD, 2017, p. 133): "o organismo, a significância e a subjetivação" (DELEUZE; GUATTARI, 2012, p. 25). A valsa da escrita artaudiana, de um corpo sem deus, sem órgãos, sem juízo, nos faz andar à beira de um abismo engenhoso, onde forças que promovem um estrangulamento político pretendem nos manter no limbo do cansaço.

Artaud nos faz experimentar o extremo do abandono, do desamparo, do desespero. "O sentimento desta desolação e deste mal-estar inominável, qual grito, digno do ladrar de um cão num sonho, te arrepia a pele, te revira a garganta, no extravio de um afogamento insensato" (ARTAUD, 2014, p. 214). Com seu Teatro da Crueldade,

quer recompor universos de subjetivação artificialmente rarefeitos e ressingularizados. [...] catalisar operadores existenciais suscetíveis de adquirir consistência e persistência. [...] invenção de novos focos catalíticos suscetíveis de fazer bifurcar a existência. Uma singularidade, uma ruptura de sentido, um corte, uma fragmentação, a separação de um conteúdo semiótico (GUATTARI, 2012, p. 30-31).

Como então pensar em tempos de niilismo? e de que modo e até que ponto a experimentação do niilismo funciona como um agenciamento de forças que desembocam na constituição do corpo intenso? "A angústia que se aproxima e se distancia cada vez mais densa, cada vez mais pesada e mais ingurgitada. É o próprio corpo que chegou ao limite de sua distensão e de suas forças e que precisa, apesar de tudo, ir mais longe" (ARTAUD, 2014, p. 213). Segundo Pelbart,

O niilismo em Nietzsche tem um caráter sabidamente equívoco. Por um lado, ele é sintoma de decadência e aversão pela existência, por outro e ao mesmo tempo, é expressão de um aumento de força, condição para um novo começo, até mesmo uma promessa. [...] Não me parece absurda a hipótese de que parte do interesse que ainda desperta o arauto da transvaloração se deva a esse traço tão contemporâneo de seu pensamento, no qual o declínio e a ascensão, o colapso e a emergência, o fim e o começo coexistem em um embate irresoluto (PELBART, 2016, p. 101).

A proposta do nosso trabalho é produzir uma conversação entre Deleuze e Guattari e Artaud, enquanto 'conversadores' de uma prosa em comum: a vida. Partindo-se desse encontro, discutiremos o conceito de devir-revolucionário. A ideia é pensar Artaud enquanto intercessor, personagem conceitual importante para pensarmos em Deleuze o esgotamento ${ }^{3}$. Será possível fazer

\footnotetext{
${ }^{3}$ Sabemos que Deleuze trata do problema do esgotado/esgotamento num texto dedicado ao Beckett. Mas a ideia é utilizar ou direcionar o conceito para algumas questões apontadas pelo Artaud.
} 
dessa despotencialização, dessa melancolia, um signo possibilitador de uma transvaloração dos valores? Porque é no esgotamento que vivenciaremos a experiência-limite entre a vida e a morte. "Uma transvaloração de valores só pode realizar-se se existe uma tensão de novas necessidades, de novos insatisfeitos, que sofrem da antiga valorização, sem disso tomar consciência [...]" (PELBART, 2016, p. 103). O esgotamento é a experiência de que o possível se extinguiu. A experiência-limite afirma o ser limitado, ela fala em transgressão ${ }^{4}$. Não o encontraremos na prateleira da transcendência. Numa teleologia. Numa promessa. Numa crença. Nas ilusões dos discursos de esperança. Desse modo, há, portanto, quatro modos de esgotar o possível: a- formar séries exaustivas de coisas, b- estancar os fluxos da voz, c- extenuar as potencialidades do espaço, d- dissipar a potência da imagem (o esgotado é: exaustivo, o estancado, o extenuado e o dissipado). Não obstante, a partir do momento em que exaurimos o possível, o esgotamento fará com que se possa sentir na superfície a força destruidora das máquinas de sobrecodificação. É justamente nesse limite (como tão bem nos mostrou Artaud), que se experimentará um tipo de erupção; a potência de uma transformação, de um desvio. É aí que o corpo 'trai o pacto', inventa e expressa uma espécie de segredo que faz àquilo que é público enlouquecer. É a maneira de afirmar uma negação que já não tem mais nada a negar. É a experiência vivida pela potência intensiva do esgotamento. A partir dessa experimentação daquilo que é insuportável que é possível atingir um avesso do niilismo. Somente nos termos da experiência dos limites que a reflexão acontece.

É preciso estar esgotado para esgotar o possível, para esgotar a combinatória. São disjunções inclusas em um mesmo eu e que precisam o decompor. Deleuze/Guattari/Artaud, nos propõem a pensar um esgotamento que nos levará à multiplicidade e à intensidade. Um devir-revolucionário se daria por agenciamentos inventados a partir de um outramento de enunciações das mais diversas, levando-nos à dissolução de um Eu. As potências da vida seriam liberadas a partir de uma experimentação da inexistência. Desfazer-se da forma-homem exige a mesma violência que foi necessária para estabelecê-la. É rasgar "a tranquilidade contínua do processo histórico" como afirma Sabot (2003, p. 20), a respeito de Foucault quando este nos diz que há uma história dos limites: "A disjunção torna-se inclusa, tudo se divide - mas em si mesmo. [...] Talvez seja como o avesso e o direito de uma mesma coisa: um sentido ou uma ciência aguda do possível, junta, ou melhor, disjunta a uma fantástica decomposição do eu. (DELEUZE, 2010, p. 69-72).

Deleuze vê no esgotamento uma potência capaz de parir o devir-revolucionário. “[...] $\mathrm{O}$ esgotamento: combina-se o conjunto das variáveis de uma situação, com a condição de renunciar a qualquer ordem de preferência e a qualquer objetivo, a qualquer significação" (DELEUZE, 2010, p. 67-69). Cansar o cansaço, gastar e esgotar o esgotamento, seria esgotar/experenciar, todas as possibilidades para a partir de ponto onde se extrapola o limite abrir espaço para o plano de criação do novo. "Sobre um acontecimento basta dizer que ele é possível, pois ele só ocorre confundindose com nada e abolindo o real ao qual pretende. Só há existência possível" (DELEUZE, 2010, p. 69). Como em uma lógica de análise combinatória. "A combinatória é a arte ou a ciência de esgotar o possível, por disjunções inclusas. Mas apenas o esgotado pode esgotar o possível, pois renunciou a toda necessidade, preferência, finalidade ou significação" (DELEUZE, 2010, p. 71).

O devir-revolucionário é a experiência do esgotamento de uma vida que não suporta mais os dispositivos que segmentam a sensação do cansaço: ao experimentar o esgotamento, linhas de articulação e de fuga se implicam por devir. "Esgotar o possível. [dar] ao possível uma realidade que lhe seja própria, precisamente esgotável, 'minimamente menor, não mais direcionada para a inexistência como o infinito para zero"” (DELEUZE, 2010, p. 75). Falamos de práticas micropolíticas efeito de uma vida levada à experiência-limite. Gilles Deleuze propõe a criação de

\footnotetext{
${ }^{4}$ Nessa relação limite-transgressão, Foucault nos diz que “a morte de Deus não foi apenas o 'acontecimento' que suscitou, sob a forma que conhecemos, a experiência contemporânea: ela delineia indefinidamente sua grande nervura esquelética" (FOUCAULT, 2009, p. 30).
} 
linhas de fuga através da resistência. "Resistir significa extrair desse homem as forças de uma vida mais afirmativa. [...] a forma-homem aprisionou a vida e, por isso, seria preciso livrar-se do homem para liberar a vida" (DELEUZE, 1988, p. 140). Para Artaud nenhuma revolução será significativa enquanto a anatomia do homem não for refeita. Esta é a conclusão que Artaud chega em sua transmissão radiofônica Para acabar com o julgamento de Deus (1948).

[...] agora é preciso emascular o homem. [...] Colocando-o de novo, pela última vez, na mesa de autópsia para refazer a sua anatomia. O homem é enfermo e mal construído. Temos que nos decidir a desnudá-lo para raspar esse animalúculo que o corrói mortalmente, Deus E juntamente com deus os seus órgãos [...] não existe coisa mais inútil que um órgão. Quando tiverem conseguido um corpo sem órgãos. Então o terão libertado de seus automatismos E devolvido sua verdadeira liberdade. Então poderão ensiná-lo a dançar às avessas. Como no delírio dos bailes populares e esse avesso será Seu verdadeiro lugar (ARTAUD, 2019, p. 196).

O juízo de Deus, "o sistema do juízo de Deus, o sistema teológico, é precisamente a operação Daquele que faz um organismo, uma organização de órgãos [...]” (DELEUZE; GUATTARI, 2012, p. 24). O organismo é o juízo de Deus, não é o corpo, é um "estrato sobre o $\mathrm{CsO},[\ldots]$ um fenômeno de acumulação, de coagulação, de sedimentação que lhe impõe formas, funções, ligações, organizações dominantes e hierarquizadas, transcendências organizadas para extrair um trabalho útil. Os estratos são liames, pinças" (DELEUZE; GUATTARI, 2012, p. 24). Quando Artaud atinge esse ponto da sua obra, desenvolvendo sua luta contra os órgãos, faz um chamado a uma revolução micropolítica, o limiar radical da potência da crueldade na criação do corpo intensivo: o CsO como esse devir intensivo, devirrevolucionário. É justamente na revolução micropolítica, na revolução corporal de cada pessoa, uma singularidade que comporta o devir revolucionário. A esse respeito Levy nos diz que: "Resistir é devir outro, é despertar o outro que existe em nós mesmos, como o impensado que existe no pensamento. Resistir é tornar-se estrangeiro, estranho na própria cultura, é devirmenor, tornar-se nômade, exilado, errante" (LEVY, 2011, p. 137). Nessa direção, podemos afirmar que um corpo esgotado ao constituir uma nova distribuição dos afetos provoca um acontecimento político. E o que dá o tom dessa nova distribuição é a ideia 'do intolerável'. O intolerável é um efeito da experiência-limite do esgotamento, portanto, um acontecimento político. Alguma coisa se passa de tal maneira que um corpo percebe o que continha de intolerável. É quando o exprimível de uma situação irrompe bruscamente. "A única oportunidade dos homens está no devir revolucionário, o único que pode conjurar a vergonha ou responder ao intolerável" (DELEUZE, 2013, p. 215).

Não existe o cosmos e cada homem é seu próprio mundo sozinho. Cabe-lhe, portanto, a sua iniciação fazendo-se viver, ou seja, criando os braços, as mãos, o pé e a respiração de sua pessoa e inexpugnável vontade. [...] A atividade surrealista era revolucionária com a condição de reinventar tudo sem mais obedecer em nenhum ponto a alguma noção trazida pela ciência, a religião, a medicina, a cosmografia etc. E [há] nesse ponto uma revolução ainda a ser feita com a condição de que o homem não se pense revolucionário somente no plano social, mas que ele acredite que ele deve sê-lo, sobretudo no plano físico, fisiológico, anatômico, funcional, circulatório, respiratório, dinâmico, atômico e elétrico [...] (ARTAUD, 2017, p. 127). 
A implicação Deleuze/ Guattari/Artaud carrega o avesso de uma biopolítica". "Não se trata de ultrapassar ou de reverter seja lá o que for, mas de revirar [...] percorrer a outra face [...], o fora" (LAPOUJADE apud PELBART, 2016, p. 15 - grifo do original). De confronto ao limite, colocamo-nos no fronte do experimento de explorar um lado de fora de uma experiência possível: a experiência-limite como uma "experiência do fora" "Forças em relação com outras forças ${ }^{7 ”}$ (DELEUZE, 1988, p. 94).

O novo paradigma estético tem implicações ético-políticas porque quem fala em criação, fala em responsabilidade da instância criadora em relação a coisa criada, em inflexão de estado de coisas, em bifurcação para além de esquemas pré-estabelecidos e aqui, mais uma vez, em consideração do destino da alteridade em suas modalidades extremas. Mas essa escolha ética não mais emana de uma enunciação transcendente, de um código de lei ou de um deus único) e todo-poderoso. A própria gênese da enunciação encontra-se tomada pelo movimento de criação processual. (GUATTARI, 2012, p. 123).

Ao possibilitar a "convergência sobre um "plano de consistência"” (DELEUZE; GUATTARI, 2011, p. 18) damos corpo a uma tentativa de mapear, cartografar as diversas direções que latejam no horizonte vertiginoso do "declínio histórico-filosófico de uma matriz metafísica de negação da vida" (PELBART, 2016, p. 14). A partir de um discurso que vai em direção ao desvencilhamento das clausuras dos corpos, das normalizações e marginalizações das condutas e biopolítica como prática social.

[...] Face a essas convulsões, a melhor atitude consiste em visar ao trabalho de cartografia e de modelização psicológica em uma relação dialética com os interessados, os indivíduos e os grupos concernidos, quer dizer, indo no sentido de uma cogestão da produção de subjetividade, renunciando as atitudes de autoridade, de sugestão [...] (GUATTARI, 2012, p. 22).

Trata-se de um encontro em que o desejo outrora aprisionado no universo da falta e territorializado pela maquinaria capitalística consegue escapar à produção de subjetividade, esta, tornada uma subjetividade sobrevivente. Um corpo sobrevivente. Um corpo sem órgãos. Como se os afectos desse 'outro corpo' fossem uma flecha que os atravessa. E um dos efeitos é àquele do corpo em entender sua própria condição de existência assubjetiva. Trata-se muito menos de uma tomada de consciência do que a explosão de uma nova sensibilidade. "O CsO é o campo de imanência do desejo, o plano de consistência própria do desejo (ali onde o desejo

\footnotetext{
${ }^{5}$ Foucault nos aponta para um terrível emaranhado. Estamos presos na armadilha do saber e do poder. Nossas vidas se encontrariam presas num tipo de areia movediça. A biopolítica, talvez a forma mais hábil de atingir os vivos é um exemplo claro de que estamos sitiados. Nossas vidas estariam sitiadas por um conjunto de dispositivos que pretendem nos governar, nos gerir. Mas o que nos toma de imediato é o seguinte problema: podemos, de certo modo, pensar uma maneira de se escapar desses dispositivos? Deleuze/Guattari/Artaud nos convidam justamente às práticas e fabulações que implodem o conjunto de dispositivos biopolíticos: o Estado e seus estratos. Falamos da constituição de um espaço liso. É nesse espaço que se configuram novas forças. Se Foucault fala de biopolítica, Deleuze/Guattari /Artaud nos incitaria à biopotência.

${ }^{6}$ Não se trata de uma simples exterioridade, e sim de uma dimensão disforme, onde circulam uma pluralidade de forças, singularidades resistência capazes de provocar rupturas em relações já estabelecidas. "O pensamento do exterior quebra os vínculos entre os signos e as normas, e com isso a ordem dos códigos e condutas” (FOUCAULT, 1984, p. 37-40).

7 "O lado de fora diz respeito à força: se a força está sempre em relação com outras forças, as forças remetem necessariamente a um lado de fora irredutível, que não tem mais sequer formas, feito de distâncias indecomponíveis através das quais uma força age sobre outra ou recebe a ação de outra” (DELEUZE apud LEVY, 2011, p. 85). “[...] A experiência do fora é a experiência impessoal, que se abre ao outro, ao desconhecido" (LEVY, 2011, p. 137).
} 
se define como processo de produção, sem referência a qualquer instância exterior, falta que viria torná-lo oco, prazer que viria preenchê-lo)" (DELEUZE; GUATTARI, 2012, p. 18). O CsO é pura multiplicidade, imanência. O corpo é constituído por uma síntese dessas relações de multiplicidade. Assim se dará a individuação do corpo. Sempre a partir de um conjunto de enunciações coletivas. Um corpo com suas conexões, sem parar. Novas travessias e travessuras. Porque um corpo precisa ser pensado a partir da ideia de que ele comporta uma infinidade de partículas, que são também, outros modos de outros corpos. Qualquer corpo, na sua individualidade é definido por essas relações cinéticas e dinâmicas.

Deleuze/Guattari/Artaud nos falam de conexões intensivas, de borda, de meio, do fora, do dentro. Em ambos, encontraremos uma tentativa de cartografar as diversas direções que latejam nos mais variados platôs. Partindo-se de uma 'negação da vida' a partir das forças que agem sobre ela, eles afirmam uma biopotência.

Quando a literatura, a arte em geral ou o pensamento alcançam a experiência do fora, colocam em xeque o presente para pensar novas maneiras de existir. Inventar novas dobras, novos estilos de vida, novos modos de existência são maneiras de resistir ao intolerável do presente. É preciso, portanto, criar novas estratégias de subjetividade, para que se possa escapar do aprisionamento em que o presente nos confina. [...] Abrir o pensamento ou a arte para as forças do fora significa chamar a vida à transformação, colocar em prática estratégias de resistência. Ou, nas palavras de Deleuze e Guattari, fazer do pensamento e da arte verdadeiras máquinas de guerra. (LEVY, 2011, p. 136-137).

É o corpo intensivo enquanto produto de intensidades que se dão na travessia do niilismo. No meio de uma crise, onde "nada mais parece possível [...] o que nós tomamos como produção mórbida, a formação do delírio, é em realidade a tentativa de cura, a reconstrução [...] ao mesmo tempo, se cruzam as transformações em curso" (PELBART, 2016, p. 39). Cada qual carrega em si as pulsões necessárias a superação da sua própria condição. Acontecimentos-resistência a partir da liberação de novas potências do corpo. "O corpo é tão-somente um conjunto de válvulas, represas, comportas, taças ou vasos comunicantes" (DELEUZE; GUATTARI, 2012, p. 16). A ideia é revirar, torcer. Possibilitar a convergência, a divergência, a disparidade e a ressonância que envolvem um plano de consistência.

O mundo contemporâneo, emaranhado em seus impasses ecológicos, demográficos, urbanos, incapaz de assumir as extraordinárias mutações técnico-científicas que o atingem, de uma forma compatível com os interesses da humanidade, se engajou em uma corrida vertiginosa, seja para o abismo, seja para uma renovação radical. As bússolas econômicas, sociais, políticas, morais, tradicionais se desorientam umas ap6s as outras. Torna-se imperativo refundar os eixos de valores, as finalidades fundamentais das relações humanas e das atividades produtivas (GUATTARI, 2012, p. 106).

Deleuze/Guattari/Artaud como uma espécie de novos cartógrafos de uma vida que ainda estaria por vir. Falamos de um tipo de vidência.

A potência estética de sentir, embora igual em direito as outras - potências de pensar filosoficamente, de conhecer cientificamente, de agir politicamente -, talvez esteja em vias de ocupar uma posição privilegiada no seio dos Agenciamentos coletivos de enunciação de nossa época (GUATTARI, 2012, p. 116). 
O esgotamento como irrupção para atingirmos esse estado de superação da vida. A ativação no esgotamento é uma vibração intensiva, é poder dizer um sim à vida em meio a sua tragicidade. Caminha sempre aos lados da destruição a tarefa da criação, as forças de criação. "Meus territórios estão fora de alcance, e não por serem imaginários; ao contrário, porque eu os estou traçando" (DELEUZE; GUATTARI, 2012, p. 79).

\section{Referências}

ARTAUD, A. Quem, no seio... In: GUINSBURG, J.; TELESI, S. F.; MERCADO NETO, A. Linguagem e vida. Trad. J Guinsburg. São Paulo: Perspectiva, 2014. p. 213-217.

ARTAUD, A. A perda de si: cartas de Antonin Artaud. Trad. Ana Kiffer e Mariana Patrício Fernandes. Rio de Janeiro: Rocco, 2017.

ARTAUD, A. Para acabar com o julgamento de Deus. In: WILLER, C. (Org.); (notas). Escritos de Antonin Artaud. Trad. Claudio Willer. 2. ed. Porto Alegre: L\&PM, 2019. p. 174-197.

DELEUZE, G. Foucault. Trad. C. Sant'Anna Martins. São Paulo: Brasiliense, 1988.

DELEUZE, G. Sobre o teatro: um manifesto de menos; o esgotado. Trad. Fátima Saadi, Ovídio de Abreu e Roberto Machado. Rio de Janeiro: Zahar, 2010.

DELEUZE, G. Controle e devir. In: DELEUZE, G. Conversações. Trad. Peter Pál Pelbart. 3. ed. São Paulo: Editora 34, 2013. p. 213-222.

DELEUZE, G.; GUATTARI, F. Mil platôs: capitalismo e esquizofrenia 2, vol. 1. Trad. Ana Lúcia de Oliveira, Aurélio G. Neto e Celia Pinto Costa. 2. ed. São Paulo: Editora 34, 2011.

DELEUZE, G.; GUATTARI, F. Mil platôs: capitalismo e esquizofrenia 2, vol. 3. Trad. Aurélio G. Neto, Ana Lúcia de Oliveira, Lúcia Cláudia Leão e Suely Rolnik. 2. ed. São Paulo: Editora 34, 2012.

FOUCAULT, M. Prefácio a transgressão. In: MOTTA, M. B. (Org.). Ditos e escritos III estética: literatura e pintura, música e cinema. Trad. Inês A. D. Barbosa. 2. ed. Rio de Janeiro: Forense Universitária, 2009. p. 28-59.

FOUCAULT, M. L'usage des plaisirs: histoire de la sexualité 2. Paris: Éditions Gallimard, 1984.

GUATTARI, F. Caosmose: um novo paradigma estético. Trad. Ana Lúcia de Oliveira e Lúcia Cláudia Leão. 2. ed. São Paulo: Editora 34, 2012.

LEVY, T. S. A experiência do fora: Blanchot, Foucault e Deleuze. Rio de Janeiro: Civilização Brasileira, 2011.

PELBART, P. P. O avesso do niilismo: cartografias do esgotamento. 2. ed. São Paulo: n-1 Edições, 2016. 
SABOT, P. La littérature aux confins du savoir: sur quelques “dits \& écrits” de Michel Foucault. In: MOREAU, P.-F. (ed.). Lectures de Michel Foucault: sur les "dits \& écrits", vol. 3. Lyon: Open Edition Books, 2003, p. 17-33.

\section{Sobre os autores}

Alex Fabiano Jardim. Doutor em Filosofia. Professor do Departamento de Filosofia, do Mestrado Profissional em Filosofia e do Mestrado em Letras/Estudos Literários pela Universidade Estadual de Montes Claros, MG.

E-mail: alex.jardim38@hotmail.com.

Michelle Martins de Almeida. Acadêmica do curso de graduação em Filosofia pela Universidade Estadual de Montes Claros (Unimontes) e membro integrante do Laboratório de Filosofia, Ciências Humanas e Outros Sistemas de Pensamento da Universidade Estadual de Montes Claros.

E-mail: michelle.mmartinss@yahoo.com.br. 